\title{
Study on the waterlogging operation effects of InfoWorks ICM dispatching strategies
}

\author{
Hui Yang ${ }^{1 *}$, Xin Tong ${ }^{1}$, Defei Gou ${ }^{1}$ \\ ${ }^{1}$ School of municipal and environmental engineering, Shenyang Jianzhu University, Shenyang, Liaoning, 110168, China
}

\begin{abstract}
In this paper, we select the $\mathrm{H}$ river basin of a city in northern China as the test section of deep tunnel construction project and use InfoWorks ICM to establish a two-dimensional hydraulic model in the basin. The basin is divided into 9 subsystems from T1 to T9 for ease of research, study the waterlogging control effect of the optimal dispatching operation strategies of deep tunnel in the basin. The results show that the waterlogging control effect meets the construction target of deep tunnel project, after the drainage of deep tunnel, the rainfall recurrence period of waterlogging risk of each subsystem is increased from more than once every year to once every ten years.
\end{abstract}

\section{Introduction}

InfoWorks ICM was developed by a UK firm, Wallingford, it applied to the design and planning of urban drainage system [1]. Compared with other models, InfoWorks ICM can couple the urban drainage system model with the river model, more realistically simulate the dynamic process of surface and underground drainage system in operation [2]. Based on the InfoWorks ICM hydraulic model, the current dispatching operation strategy and the deep tunnel joint operation dispatching strategies are compared, the effect of waterlogging control in different recurrence periods and whether it can meet the construction target of deep tunnel project are investigated.

\section{Model establishment}

The InfoWorks ICM is used to build a one-dimensional drainage system model, it is based on manholes and drainage pipes in a drainage pipe network, and relevant drainage facility property data such as pump station, weir, valve, tap door, etc, and combined with the information of river, lake, and surface water confluence characteristics, etc. Based on one-dimensional model, elevation point (X, Y, Z) data were extracted, and GIS spatial analysis tool was used to make surface digital elevation model (DEM), which was coupled with one-dimensional drainage model and divided into irregular triangular grids. A twodimensional hydraulic model that can simulate the dynamic process of surface water immersion was established [3-4], the planar map and the partial magnification map of the two-dimensional model are shown in Fig. 1 and Fig. 2.

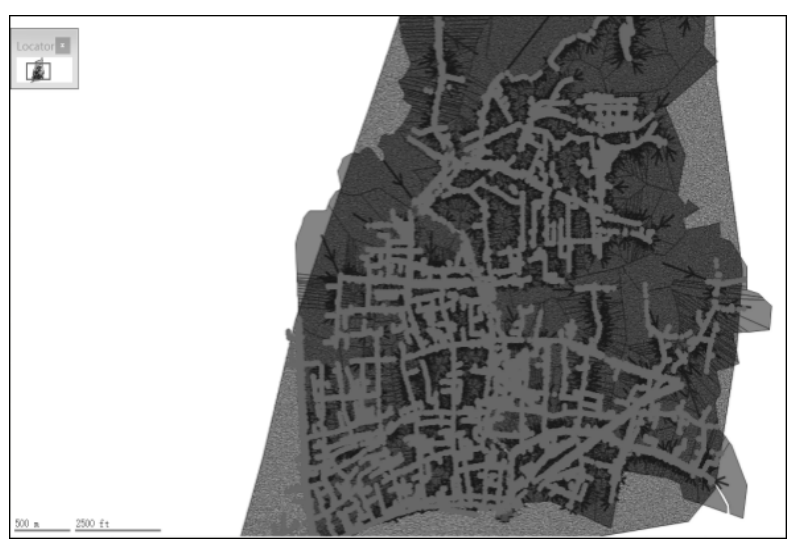

Fig1. The planar map of 2D drainage system model of $\mathrm{H}$ river

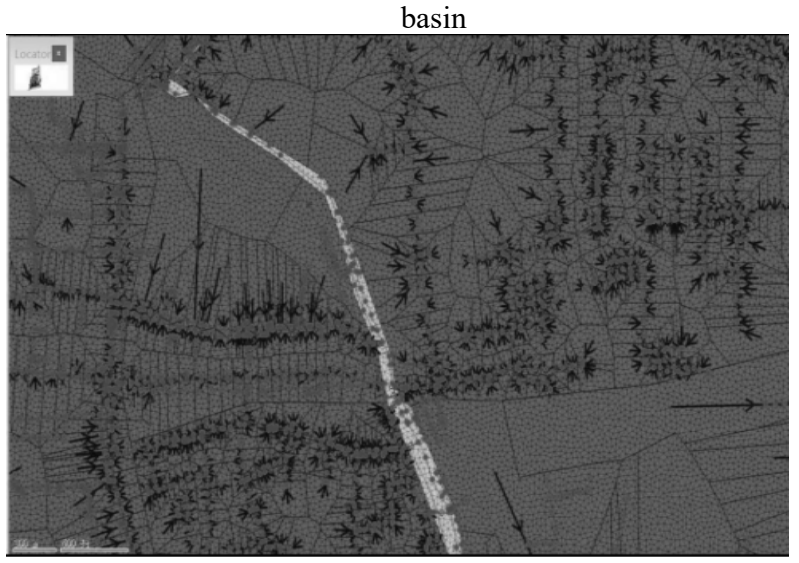

Fig2. The partial magnification map of 2D drainage system model of $\mathrm{H}$ river basin

\section{Establishment of detection system}

According to the experience of dispatching operation of deep tunnel system abroad, the waterlogging monitoring and research of deep tunnel drainage system are carried

\footnotetext{
${ }^{*}$ Corresponding author: yanghui-73@163.com
} 
out [5]. Based on the investigation and analysis of waterlogging situation of shallow pipe network in the $\mathrm{H}$ river basin, reasonable waterlogging points in the basin were selected, monitoring points were installed, and a real-time monitoring system of drainage pipe network was established. The real-time monitoring function of rainfall and liquid level in the monitoring system is used to study the real-time operation strategies of optimal dispatching of drainage system.

\section{Divide subsystems}

For the ease of research, the $\mathrm{H}$ river basin can be divided into nine subsystems from $\mathrm{T} 1$ to $\mathrm{T} 9$ according to the decentralized control theory of the large system, and the distribution of controllable facilities in the large drainage system, the adjustable range and the distribution of drainage pipe line. T1 and T2 are subsystems of the pump station; From T3 to T6 are subsystems of the shaft, and it $\mathrm{H}$ river basin is directly connected with the deep tunnel; T7 and T9 are subsystems of the lake; T8 is the subsystem of the lifting pump station. The subsystem division is shown in Fig. 3.

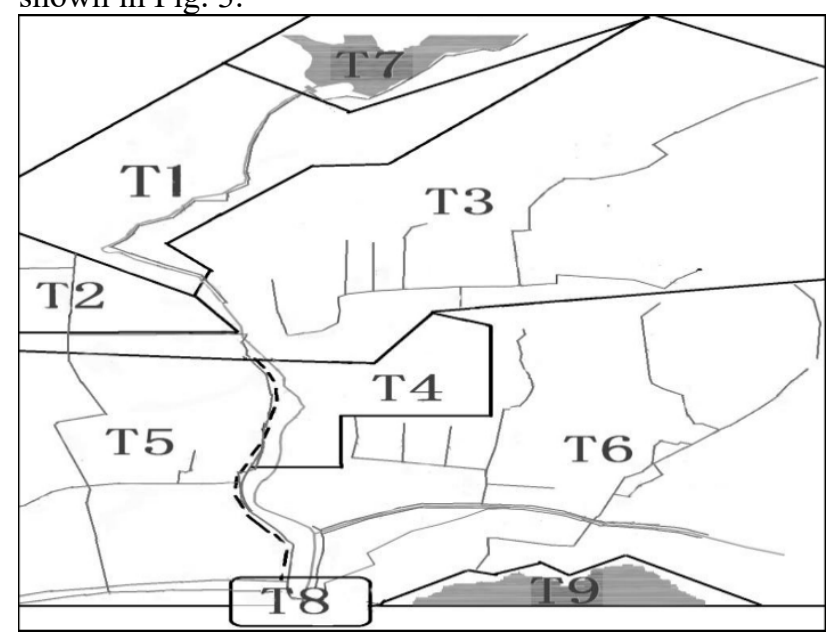

Fig3. Division diagram of drainage system in $\mathrm{H}$ river basin

\section{Study on the effects of waterlogging control}

The deep tunnel drainage system in $\mathrm{H}$ river basin is currently under construction transformation, so dispatching operation strategies cannot be applied in practice and verified temporarily. Therefore, in order to evaluate the implementation effect of dispatching operation strategies, the InfoWorks ICM hydraulic model was used to evaluate and compare the implementation effect of the current dispatching strategy and the deep tunnel joint operation dispatching strategies in the basin. The effect evaluation is mainly aimed at the effect of waterlogging control in the basin under different recurrence periods, and it is also investigated whether the operation of deep tunnel combined with shallow drainage pipe network can meet the construction target of deep tunnel project.

The deep drainage system is a supplement and upgrade to the shallow drainage system. Therefore, the basic rules of optimal scheduling are as follows: the shallow drainage system executes before the deep tunnel drainage system, that is, the deep tunnel system executes only when the shallow drainage system is insufficient.

According to the deep tunnel has the functions of storage and draining water, the dispatching process is divided into two parts: "storage operation of deep tunnel" and "drainage operation of deep tunnel". Among them, The basic operation process of deep tunnel storage is: from the beginning of the deep tunnel inflow until the deep tunnel capacity reaches the design capacity limit,finally to close the deep tunnel shaft inlet gate process. During this period, only the emptying pump group is opened at the lifting pump station at the end of deep tunnel. The basic operation process of deep tunnel drainage is: On the basis of storage operation, shallow dispatching facilities have opened (generally refers to the intercepting valve has been opened to discharge the flood into the river), the rain continued, target control points happening again waterlogging, or the waterlogging have become more severe, it is necessary to open the inlet gate of the deep tunnel again for drainage, during this period, the drainage pump group in the drainage pump station will start to operate, while the emptying pump group will be determined whether to continue to operate according to the deep tunnel inflow flow rate and the drainage pump group's lifting capacity.

The current operation strategy (no deep drainage tunnel) and the optimized dispatching operation strategies of deep tunnel were respectively edited in the InfoWorks ICM hydraulic model RTC editor, the simulation operation of rainfall with a recurrence period of $\mathrm{P}=0.25$ years, 0.5 years, 1 year, 2 years, 5 years, 10 years, 20 years and 50 years with a rainfall duration of $120 \mathrm{~min}$ was carried out. According to the simulation results, the waterlogging occurrence of each subsystem in the $\mathrm{H}$ river basin was analyzed and counted.Under the current strategy, the optimized dispatching operation strategy of deep tunnel storage, and the optimized dispatching operation strategy of deep tunnel drainage, the risk level maps of waterlogging in the basin under different rainfall recurrence periods are shown in Fig. 4 and Fig. 5.

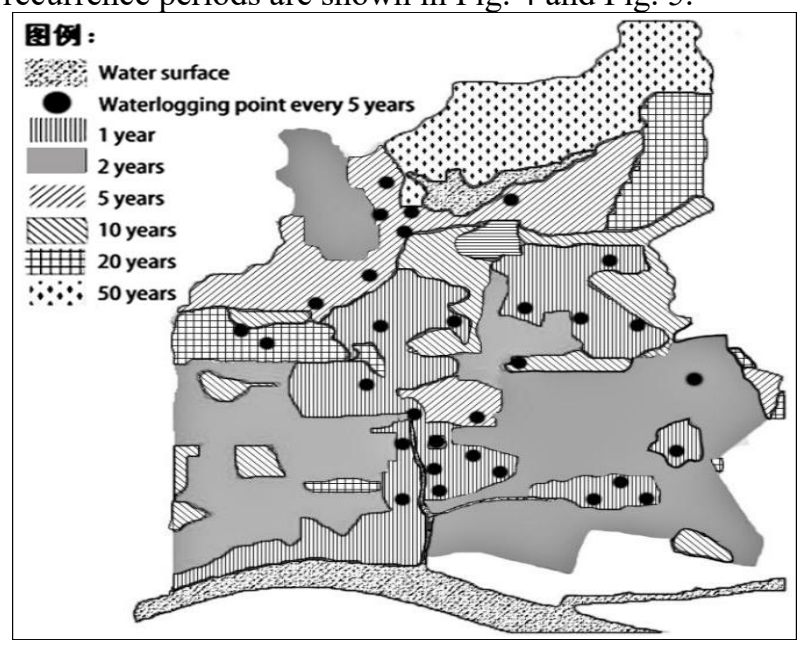

Fig4. Risk level map of waterlogging under different rainfall return periods in $\mathrm{H}$ river basin (current situation) 


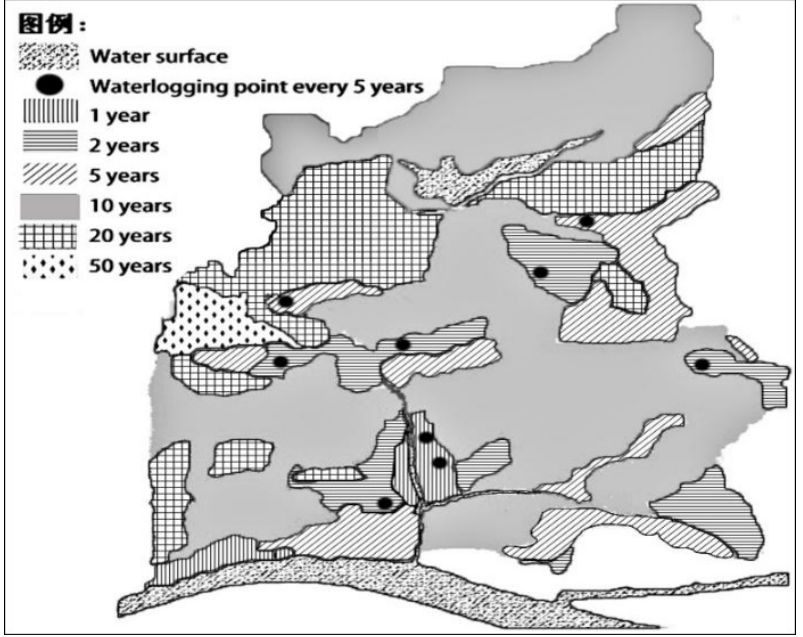

Fig5. Risk level map of waterlogging under different rainfall return periods in $\mathrm{H}$ river basin (after drainage)

From Fig. 4, according to the current strategy operation condition of drainage pipe network in $\mathrm{H}$ river basin, the recurrence period of waterlogging is more than once every year, high risk of waterlogging, in the intensity of rainfall that occurs once every five years, there are 32 waterlogging points that are more severe. Under the optimized dispatching operation strategies of deep tunnel, after the deep tunnel storage, the waterlogging recurrence period is basically increased to less than once every 2 years, and the risk of waterlogging in each subsystem is obviously reduced. From Fig. 5, after using deep tunnels to drain water, the recurrence period of waterlogging risk in each subsystem is basically increased to once every 10 years, in the intensity of rainfall that occurs once every five years, there are only 9 waterlogging points that are more severe.

Through analysis, among them, 8 waterlogging points are mainly caused by the diameter of the pipe is too small, in low-lying river basins, and located in the edge of the basin and so on. Such as the waterlogging point FB-1 shown in Fig. 6, it can be seen that this point is low-lying. The Fig. 7 shows the hydraulic profile of the section of pipe under pressure under the rainfall intensity that occurs once every 5 years, from the picture, we can see that waterlogging occurs at this point is due to low-lying terrain and too small diameter. For similar the point, it is difficult to eliminate waterlogging by dispatching facility, it is suggested that the site pipe section should be reformed.

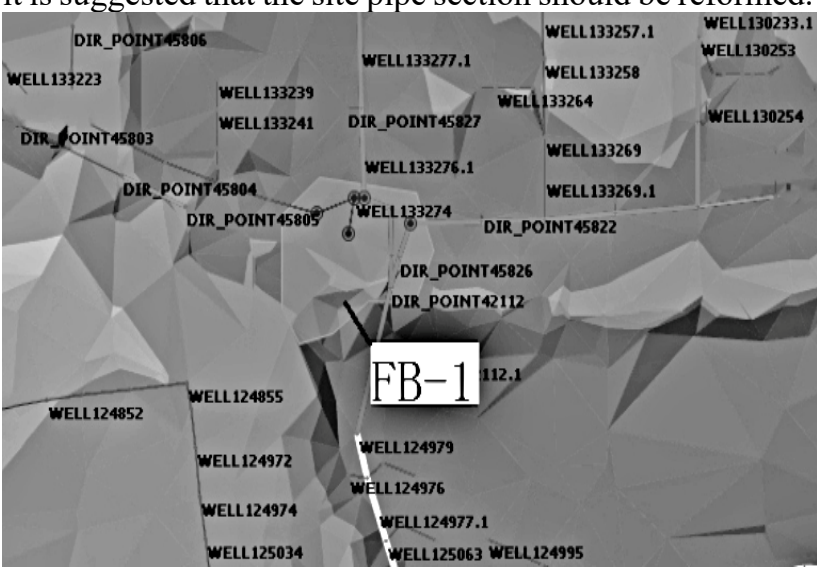

Fig6. Geographical model at point FB-1

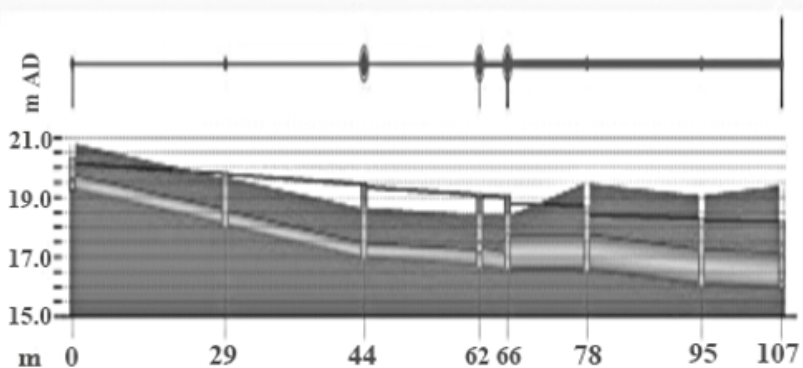

Fig7. Hydraulic profile of pressure pipe section at point FB-1 under 5-year rainfall

Compare and analyze the results, the statistical results are shown in table 1 . The subsystems for statistical analysis only include T1-T6 subsystems, the T7, T8, T9 don't directly reflect waterlogging problems, so they are not reflected in the table.

Table1. Comparison and statistics of different dispatching strategies for waterlogging control

\begin{tabular}{|c|c|c|c|}
\hline \multirow{2}{*}{ Subsystem } & \multicolumn{3}{|c|}{ Waterlogging recurrence period P } \\
\cline { 2 - 4 } & $\begin{array}{c}\text { The current } \\
\text { strategy }\end{array}$ & $\begin{array}{c}\text { Optimized dispatching operation } \\
\text { strategies of deep tunnel }\end{array}$ \\
\cline { 3 - 4 } & $\begin{array}{c}\text { Under the } \\
\text { storage } \\
\text { condition }\end{array}$ & $\begin{array}{c}\text { Under the } \\
\text { drainage } \\
\text { condition }\end{array}$ \\
\hline $\begin{array}{c}\text { Pump station } \\
\text { subsystem T1 }\end{array}$ & 1 year & 5 years & 20 years \\
\hline $\begin{array}{c}\text { Pump station } \\
\text { subsystem T2 }\end{array}$ & 5 years & 10 years & 50 years \\
\hline $\begin{array}{c}\text { Shaft subsystem } \\
\text { T3 }\end{array}$ & 0.25 years & 2 years & 10 years \\
\hline $\begin{array}{c}\text { Shaft subsystem } \\
\text { T4 }\end{array}$ & 1 year & 5 years & 10 years \\
\hline $\begin{array}{c}\text { Shaft subsystem } \\
\text { T5 }\end{array}$ & 0.5 years & 2 years & $\begin{array}{c}\text { More than } 5 \\
\text { years }\end{array}$ \\
\hline $\begin{array}{c}\text { Shaft subsystem } \\
\text { T6 }\end{array}$ & 0.25 years & 2 years & 10 years \\
\hline
\end{tabular}

\section{Results analysis}

From table 1, it can be seen that under the optimal dispatching operation strategies of deep tunnel, after the drainage function of deep tunnel is exercised, the drainage standard of $\mathrm{H}$ river basin has been improved to the intensity of rainfall once every 10 years. The functions of the deep drainage tunnel project in $\mathrm{H}$ river basin are as follows: under the condition of rainstorm, as a drainage channel for rainwater, the drainage function is performed to improve the drainage standard of the confluent trunk channels in the basin to the recurrence period $\mathrm{P}=10$. Therefore, according to the results in table 1, only from the aspect of waterlogging control effect, the implementation effect of optimal dispatching operation strategies of deep tunnel meets the goal of engineering construction. 


\section{Conclusions}

According to the results of waterlogging control, after the deep tunnel exercises the storage function, the waterlogging risk in the $\mathrm{H}$ river basin is basically increased from more than once every year to less than once every 2 years under the current strategy. After the deep tunnel exercises the drainage function, the waterlogging recurrence period of the basin is basically increased to once every ten years. Therefore, the research shows that the risk of waterlogging in the basin meets the engineering construction goal of increasing the rainfall recurrence period to once every 10 years after the use of deep tunnel for drainage.

\section{Acknowledgments}

Thank you for the support of the project of water pollution treatment and water environment management technology integration and application in liaohe river basin (2018ZX07601001), and thank you for the help of teachers and students on the paper.

\section{References}

1. Zhao, W.Y. (2015)Infoworks ICM drainage network model in practice.Journal of Liaoning University (Natural Science), 42:118-122.

2. Artina, S., Bolognesi, A., Liserra, T., Maglionico, M. (2006) Simulation of a storm sewer network in industrial river basin:Comparison between models calibrated through experimental data. Environ Modelling Software, 22:1221-1228.

3. Mark, O., Weesakul, S., Apirumanekul, C., AROONNET, B.S., Djordjevic, S. (2004) Potential and limitations of $1 \mathrm{D}$ modelling of urban flooding. Journal of Hydrology, 299: 284-299.

4. Huang, G.R., Wang, X., Huang, W. (2017) Simulation of rainstorm water logging in urban river basin based on InfoWorks ICM model. Water Resources and Power, 35: 66-70.

5. Zhou, W.Y., Sun, Z.M., Tang, S. (2018) Research on liquid level on-ling monitoring system of deep tunnel drainage river basin. China Water \& Wastewater, 34: $1-6$. 